\title{
Educação popular: \\ instrumento de formação, luta e resistência no projeto educativo do MST
}

\author{
Márcia Mara Ramos iD \\ Coletivo Nacional de Educação MST \\ Universidade do Estado do Rio de Janeiro, Rio de Janeiro, RJ, Brasil
}

\begin{abstract}
Resumo
A educação popular é um importante instrumento formador e de luta, que institui processos determinantes para a formação e consolidação da história da educação brasileira. O direito e o acesso à educação pública, gratuita, laica e de qualidade têm raízes nas lutas reivindicatórias das classes populares, que combatem concepções liberais nos diferentes periodos da história. Alternativas de resistência são construidas coletivamente, utilizando estratégias de mobilização nas comunidades para realizar o trabalho de base. Este artigo visa compartilhar ideias das práxis social e coletiva de educação do Movimento Sem Terra (MST). Trata-se de uma experiência de resistência, luta e organização política em defesa da Educação do Campo: professores educadores resistem para significar o campo como lugar de vida, de produção de saberes e conhecimento. A defesa das políticas públicas, em especial da educação pública, gratuita, laica e de qualidade, em conformidade com o princípio de que educação não é mercadoria, luta histórica da classe trabalhadora, é um lema que precisa estar ativo. Requer-se a organização da categoria dos trabalhadores da educação na perspectiva de uma práxis coletiva e de organização social para articulação e construção de outro projeto educacional. Palavras-chave: educação popular; luta pela terra; coletividade; resistência.
\end{abstract}

\section{Popular education as instrument for resistance and formation in the MST educational project}

\begin{abstract}
Popular education is an important instrument which establishes processes for the formation and consolidation of the history of Brazilian education. The right and access to public education which is free, secular and has quality have their roots in the popular claims and resistance against liberalism in different periods of history. Resistance alternatives are built collectively using community mobilization strategies to do the groundwork. This article aims to share ideas of the social and collective praxis of education of the Movimento dos Sem Terra (MST)- Landless People Movement. According to this movement, education is part of political organization and resistance in defense of Country People Education: teachers and educators resist in order to show that country is a place of life, knowledge and wisdom. The defense of public policies to ensure free and secular education in which quality is a historical claim of the working class and must be always in action. The organization of educational workers is required for the collective and social praxis in order to construct another educational project.
\end{abstract}

Keywords: popular education; fight for the land; collectivity; resistance.

\section{Introdução \\ O que aduba meu pé de poesia [...] É o bagaço da cana Moido no engenho de ferro Que traz no gosto da rapadura O amargor de vida Também moídas...}

(“Estrume", DINIZ, 2017, p. 19)

A relação com a terra e seu significado para as comunidades tradicionais e campesinas liga-se à dimensão da vida, da casa, da vivência na natureza, da harmonia com o tempo e o mundo, do habitar e respeitar a terra mãe, a pacha mama dos Andes. Para essas populações, a terra não é mercadoria. A terra é o lugar de produção da vida, da existência e da produção de alimentos saudáveis. A relação com a terra funda-se em princípios comunitários, na coletividade, na invenção da vida. A luta pela terra significa o direito à existência, à resistência dos povos

\footnotetext{
^Endereço para correspondência: Rua Alameda Barão de Limeira, 1232 - Campos Elíseos, São Paulo, SP - Brasil. CEP: 01202-002 E-mail: marciapterra@gmail.com Os dados completos da autora encontram-se ao final do artigo.
}

do campo contra a propriedade privada e a concentração fundiária, que aumentam os índices da pobreza no Brasil (JIMÉNEZ, 2019).

Fazer o lugar, em particular o que chamamos de "casa", é uma arte que pertence principalmente ao povo e não ao capital, assim como certos aspectos dos lugares que chamamos de cidades são ferozmente disputados por desenvolvedores capitalistas para fornecer as infraestruturas físicas tão necessárias para ocorrer a acumulação. O significado mais profundo que as pessoas atribuem a sua relação com a terra, lugar, casa, práticas da habitação está perpetuamente em desacordo com os comercialismos crassos dos mercados de terra e de propriedades (HARVEY, 2012, p. 157).

A arte de cuidar, semear e produzir alimento para sustentar a vida não é considerada, pela lógica capitalista hegemônica, um conhecimento científico, que a classifica como um saber popular. Essa lógica parte de alguns pressupostos como, por exemplo, o de que os conhecimentos ordinários precisam da chancela acadêmica para alcançar status de ciência. Um saber científico reconhecido pelo pensamento hegemônico e capitalista argumenta, na maioria das vezes, que a tecnologia pode e deve 
estar a serviço da propriedade privada, do lucro, sem se sentir necessariamente responsável por desenvolver uma reflexão a respeito de como essa apropriação pode gerar desigualdade social.

A "Fala da terra", poema de Pedro Tierra (2014), vem como inspiração para pensar o que devemos ensinar às crianças, aos jovens e adultos e quem são as lutadoras e os lutadores defensores da terra dividida, repartida como bem comum.

\author{
A Liberdade da Terra não é assunto de lavradores. \\ A Liberdade da Terra é assunto de todos \\ quantos se alimentam dos frutos da Terra. \\ Do que vive, sobrevive, de salário. \\ Do que não tem casa. \\ Do que só tem o viaduto. \\ Dos que disputam com os ratos os restos das \\ grandes cidades. \\ Do que é impedido de ir à escola. \\ Das meninas e meninos de rua. \\ Das prostitutas. \\ Dos ameaçados pelo Cólera. \\ Dos que amargam o desemprego. \\ Dos que recusam a morte do sonho. \\ A Liberdade da Terra e a paz no campo têm \\ nome: Reforma Agrária.
}

Vivenciamos um tempo de práticas sustentadas pela intolerância, pelo ódio à diversidade e de defesa da eliminação das diferenças que nos constituem como seres humanos. Uma defesa de pós-verdades que desqualificam o conhecimento historicamente produzido pela humanidade com a intenção de que se estabeleçam retrocessos nos campos da vida cotidiana e não a superação das lógicas opressoras que nos dividem para a manutenção do status quo. Experimentamos, muitas vezes forçadamente, tempos e espaços que intensificam a "depressão social", o adoecimento mental, a produção de violência como solução para a violência do Estado burguês.

É urgente e necessário juntar as forças da classe trabalhadora para a construção de um projeto de superação do projeto hegemônico do capital. É necessária a organização de classe focada num projeto político do país, na construção da educação que possa formar sujeitos capazes de querer e saber transformar a realidade da sociedade capitalista vigente (ROSSLER, 2004).

Retomar o método do trabalho de base e a educação popular, tendo como referência a arte como instrumento político e formador das comunidades, é essencial para a formação humana omnilateral visando à construção do projeto de emancipação social como principal referência. É tempo de semear esperança, amor, e de plantar a arte insurgente. De cantar o canto da organização do povo, de ecoar o mais alto dos sons, no ritmo da dança escolhida coletivamente. É tempo de andar descalço, de celebrar as pequenas colheitas, na esperançada gestação de um mundo possível. Que mesmo que uns não queiram, veremos o "novo dia" raiar.

\section{A intencionalidade da pedagogia do capital}

O papel da educação no Brasil sempre esteve atrelado a interesses da ideologia dominante: primeiramente, a de catequizar os povos indígenas; em seguida, a de formar para o trabalho em função da industrialização; e finalmente a de se tornar uma mercadoria vital para o capital. Esse processo é histórico, mas não linear, e na atualidade mistura o arcaico com o "moderno", ou seja, o projeto neoliberal se apresenta como algo moderno e solução para o desemprego, com empreendedorismo, a "uberização" do trabalho, entre outros. Esse mesmo projeto "moderno" e ultraconservador expropria e explora a classe trabalhadora, e todos os que discordam do projeto liberal são atacados e criminalizados, como acontece com professores e estudantes que lutam em defesa da educação pública no Brasil.

O processo histórico nos dá a ver indícios de estratégias formadoras da ideologia dominante capitalista, que se reinventam com o projeto liberal e forjam as frentes de atuação da extrema direita no campo da educação, produzindo, por exemplo, imaginários sociais a respeito da formação para o empreendedorismo empresarial, ou ainda, da defesa de uma "escola sem partido", escamoteando a intenção de tornar as escolas o lugar de um partido único, de uma ideologia única e de uma forma de existência única, sempre em benefício da manutenção da ordem em que o capital dita as regras.

A educação capitalista tem como projeto central o neoliberalismo como principal referencial ideológico na formação do indivíduo, projeto educativo determinado por organismos internacionais como o Banco Mundial e o Fundo Monetário Internacional (FMI). É visível a relação de exploração do projeto do capital na vida dos profissionais da educação: duplas e exaustivas jornadas de trabalho, baixa remuneração em todos os níveis de ensino, aligeiramento na formação dos profissionais e intelectuais, sucateamento da educação pública, laica e gratuita nas diferentes instituições de ensino, retirada dos direitos trabalhistas, entre outros (ROSSLER, 2004).

A pedagogia do capital tem formado o novo sujeito moderno e necessário para o projeto de acumulação do capital. A subjetividade da pedagogia do capital se apresenta de forma objetiva na formação humana com características que sutilmente combatem a coletividade. Para Dardot e Laval (2016), destacam-se as principais características do "novo sujeito neoliberal" - "hipermoderno", "impreciso", "flexível”, "precário", "fluido", "sem gravidade" e que sofre sintomas de uma nova era, diagnosticada pela psicanálise como a "era da ciência" ou do "discurso capitalista".

O "novo sujeito moderno", produto do final do século $\mathrm{XX}$, é engendrado "na figura do homem-empresa ou do sujeito empresarial" que produz uma formação "psíquica" de um "novo tipo" que alcance o objetivo de reorganização "da sociedade, das empresas e das instituições" nas relações e comportamento mercantil. O homem neoliberal "é competitivo, inteiramente imerso na competição mundial” (DARDOT; LAVAL, 2016, p. 321-322). 
A formação do "sujeito plural" admite uma "liberdade subjetiva", como se houvesse uma "mão invisível" conduzindo o "novo governo dos homens que penetra até seu pensamento, acompanha, orienta, estimula, educa esse pensamento", não só adestrando os corpos, "mas gestando os corpos" (DARDOT; LAVAL, 2016, p. 324-325).

A subjetividade da pedagogia do capital se apresenta objetivamente nas diferentes áreas de atuação, na fusão entre cultura, comunicação, educação, alimentação, todas voltadas para o mesmo objetivo: produzir mercadorias, lucro, consumo, controle social, resultando na concentração de riquezas e desigualdades sociais. Para Mancebo (2003, p. 77), o pensamento social e político globalizado, por meio do neoliberalismo, "representa uma alternativa política, econômica, social, jurídica e cultural para a crise econômica do mundo capitalista", que atende às necessidades do capital de acumulação e restabelecimento de sua hegemonia, mas que tem implicações para a vida econômica e para as mais diversas relações entre seres humanos.

A velocidade da informação e a divulgação em massa das ideias dominantes permitem que o capitalismo continue se recompondo ao se apropriar de novas criações tecnológicas.

No plano político-cultural, pode-se afirmar que o neoliberalismo baseia-se numa constelação ideológica em que o nascimento vigoroso do mercado e do individualismo aparecem como articuladores nucleares da prática social e das relações que os homens estabelecem entre si. [...] A faceta tecnológica das mudanças globais - a nova tecnologia das comunicações e da informática, já cunhada, por muitos, de revolução da microeletrônica - vem sendo apresentada como uma das principais responsáveis por grande parte dessas novas dinâmicas. Ela tem permitido o incremento do volume e da velocidade das informações e a redução dos custos da comunicação e transporte, envolvendo o conjunto do planeta, mesmo de forma desigual; tem produzido um impacto na produção e organização industriais, na comercialização dos produtos, viabilizando a atividade especulativa (MANCEBO, 2003, p. 77-78).

A pedagogia do capital incentiva a solução de caráter individual, de fragmentação social, estimulando um tipo de participação que não apresenta ameaças à hegemonia burguesa e que, portanto, apenas aparentemente se constitui como atuação na sociedade. Ela restringe o nível de consciência política e coletiva, se apropria da fragmentação de classe e com ela se fortalece.

\section{Resistência e coletividade em movimento}

E que as crianças cantem livres sobre os muros E ensinem sonho ao que não pode amar sem dor E que o passado abra os presentes pro futuro Que não dormiu e preparou o amanhecer.

("Que as crianças cantem livres" - TAIGUARA, 2016)1

O direito de estudar e de ter escolas próximas de si foi negado historicamente às populações do campo. Considerados atrasados na história, sem acesso à saúde, edu-

\footnotetext{
"Que as crianças cantem livres" foi uma das músicas censuradas de Taiguara, em 1973, durante o período da ditadura militar, e posteriormente liberada, em 1982 Disponível em: https://www.youtube.com/watch?v=oEFPRTD6I44
}

cação, sem política agrícola e resistindo à concentração fundiária e à propriedade privada, essas populações lutam, historicamente, para "derrubar os muros", as cercas, "para serem livres". O MST luta pelo direito de haver escolas no campo, pela alfabetização dos trabalhadores, pelo seu direito de ler e escrever a sua própria história no mundo, pelo acesso à educação infantil como espaço de socialização das crianças do campo e pela universalização da educação como direito de jovens e adultos de vivenciar, nas universidades públicas, a ocupação do latifúndio do saber e contribuir para o desenvolvimento social, cultural, ambiental e econômico para o campo.

O projeto de Reforma Agrária Popular (MST, 2014) propõe a supressão da concentração fundiária e a possibilidade de a população do campo ter trabalho e moradia, direitos que historicamente foram negados pelos modos de produção do capitalismo. A questão agrária é um problema concreto para a realidade do Brasil- país de maior concentração de terra, de violência e massacres de povos do campo. A disputa entre o agronegócio que produz monoculturas como cana, soja, trigo, milho, eucalipto e gado, e a agricultura familiar camponesa, que produz $70 \%$ da alimentação que está na mesa do povo brasileiro, é muito desigual (ALVES, 2019). Além dos altos subsídios concedidos pelas políticas governamentais, o agronegócio tem todo um aparato midiático, reafirmando todos os dias que tudo é agro. "Agro é pop, agro é tech, agro é tudo..." Agro são agrotóxicos nos rios, na alimentação, no ar, na terra, no corpo dos brasileiros. $\mathrm{O}$ Brasil é o maior consumidor de agrotóxicos do mundo (ASSOCIAÇÃO PARANAENSE DOS EXPOSTOS AO AMIANTO, 2017).

Portanto, ocupar a terra é romper com a estrutura individualista de sociedade, é enfrentar o latifúndio e lutar pela desapropriação da terra, construindo outro tipo de projeto para a comunidade e a sociedade, modificando a forma de vida e de atuação social. Ocupar o latifúndio é mais que romper a cerca de arames farpados. Em certa medida, é romper com a história de subordinação total ao capital. É estar disposto a viver os valores coletivos, como dividir, respeitar as decisões do conjunto, aprender a ouvir, ser solidário, ter vontade e ousadia de continuar lutando. Os acampamentos e assentamentos se apresentam como germes/possibilidades em direção a outra forma de produzir a vida, diferente da forma hegemônica. São espaços de enfrentamento do latifúndio, das grandes transnacionais, e, ao mesmo tempo, de formação política das pessoas que dele fazem parte.

As práticas educativas do MST estão em movimento. São construídas pelos próprios sujeitos Sem Terra em decorrência da necessidade concreta da vida humana. Os estudos da educação popular, da educação socialista e da própria educação do movimento permitem que o MST lute por outro tipo de escola, desde a sua arquitetura e concepção, pelo direito de ter acesso ao conhecimento produzido pela humanidade, pela criação do espaço da Ciranda Infantil para garantir que as crianças, desde pequenas, estivessem num espaço organizativo e que as mulheres Sem Terra pudessem ter a garantia de que seus 
filhos estariam em um lugar de segurança e as motivassem a estudar, trabalhar e contribuir na direção política da organização. O MST direciona o trabalho de educação dos Sem Terra na sua base social, como também articula a luta pela Educação do Campo juntamente com outras organizações sociais e populares.

\section{Práticas de resistência coletiva}

A resistência coletiva na defesa dos territórios conquistados com luta vem sendo realizada com práticas que orientam a construção da Reforma Agrária Popular. Denunciar as formas perversas e destrutivas das práticas do capital, por meio do latifúndio e do agronegócio, não tem sido uma tarefa fácil. Ao longo dos 35 anos de existência, o MST continua mobilizando e praticando ações coletivas contra o projeto do capital.

A luta por escola no/do campo - Desde os primeiros acampamentos no Sul do país, no ano de 1984, o MST defende o direito de as crianças estudarem e luta pelo direito das famílias de terem escola nos assentamentos e acampamentos Sem Terra. A luta por escolas fez com que o MST elaborasse, coletivamente, uma concepção de educação com referência na pedagogia socialista e na educação popular. Em 2011, o MST mobilizou uma campanha nacional contra o fechamento de mais de 24 mil escolas no campo, com o lema "Fechar escola é crime!". A pesquisa de Alentejano e Cordeiro (2019) indica a gravidade do aumento desses números; entre os anos "de 1997 a 2018, foram fechadas quase 80 mil escolas do campo", no Brasil.

Diante da prática da direita de criminalizar as organizações sociais, o MST mobilizou em 2019 a campanha "Pelo Direito à Literatura nas Escolas do Campo" (PELO direito..., 2019), visando valorizar a leitura e o acesso ao livro como direito. Essa campanha envolveu o conjunto da sociedade na doação de obras de literatura para as escolas do campo.

Jornada das crianças Sem Terrinha - Desde 1994, no mês de outubro, o MST realiza atividades nos assentamentos e acampamentos, nas regiões e estados, com as crianças Sem Terrinha. Esse espaço é chamado de encontros das crianças Sem Terrinha, organizado pelas escolas e comunidades Sem Terra. São espaços de criação, estudo, brincadeiras e de reivindicação dos direitos das crianças Sem Terra. Em 2018, foi realizado o $1^{\circ}$ Encontro Nacional das Crianças Sem Terrinha, em Brasília, com mais de 1000 crianças. Esse Encontro foi motivo de ataques ao MST e às crianças Sem Terra por parte do atual governo. Além do desgaste político, da negação do direito à participação infantil na sociedade, também gerou um processo jurídico. Em 2019, a Procuradora da República Marcia Brandão Zollinger fez arquivamento do processo, considerando que:

Dessa forma, não se verifica, analisando os fatos narrados na reportagem, nenhuma violação por parte da organização do $1^{\circ}$ Encontro Nacional das Crianças Sem Terrinha aos direitos assegurados às crianças pelo Estatuto da Criança e do Adolescente e pela Constituição da República. Pelo contrário, o Movimento dos Trabalhadores Rurais Sem Ter- ra tem sido ativo ator social na luta pelo direito à educação das crianças e adolescentes do campo. Por fim, ressalte-se que o $1^{\circ}$ Encontro Nacional das Crianças Sem Terrinha está inserido no contexto das manifestações democráticas de uma sociedade plural, realizada de forma legítima, legal e constitucional (Promoção de Arquivamento n ${ }^{0} 351 / 2019$ ). ${ }^{2}$

Em 2019, além dessa conquista, o MST reafirmou o compromisso com a educação das crianças, realizando Encontros Sem Terrinha em todo o país: em São Paulo, no Paraná, em Minas Gerais, no Rio Grande do Sul, entre outros Estados. Sem Terrinha em movimento: brincar, sorrir e lutar por Reforma Agrária Popular segue como tema das mobilizações infantis e o MST.

Ciranda Infantil - Trata-se de um espaço educativo e alternativo, inaugurado em 1997, para as crianças de 0 a 6 anos. A Ciranda Infantil é um espaço pedagógico e cultural organizado nos assentamentos e acampamentos, nos encontros, marchas, reuniões e congressos, para que as crianças pequenas possam acompanhar as mães e os pais nas atividades de formação, de estudo e trabalho. A Ciranda se tornou uma referência organizativa internacionalmente, que proporciona um lugar educativo para as crianças e maior participação das mulheres no MST. No V Congresso do MST, em 2007, a Ciranda Infantil Paulo Freire reuniu mais de 1000 crianças de 0 a 12 anos de todo o Brasil, e no VI Congresso, em 2014, 700 crianças de 0 a 12 anos.

A Educação de Jovens e Adultos (EJA) - É uma frente que surgiu para valorizar o conhecimento e proporcionar aos jovens e adultos o direito de ler e escrever. A campanha "Todos os Sem Terra estudando" abraçou uma missão desafiadora para a organização Sem Terra: a de transformar as comunidades em territórios livres do analfabetismo. Foram reafirmados projetos e inauguradas experiências no trabalho com a EJA. Com base nas ideias de Paulo Freire e no projeto de alfabetização cubano Sim Eu Posso, levando em conta que a taxa de analfabetismo no Brasil é de $11 \%$ e que o maior número dessa população está no campo, o MST tem mobilizado articulações junto às prefeituras para que sejam desenvolvidos projetos de alfabetização nos municípios brasileiros.

Formação dos educadores - Mesmo com dificuldades estruturais e políticas, a luta para manter os espaços conquistados e a formação de educadores das escolas de assentamento e acampamento está na pauta do Movimento (BARBOSA, 2019). Garantir a formação dos educadores fortalece a coletividade para enfrentar os dias difíceis da atual conjuntura brasileira. Os encontros de educadores são espaços de formação que proporcionam reflexão, estudo e ações conjuntas para pensar o momento atual e fazer projeções. Assim como no Rio Grande do Sul, o MST faz a formação dos educadores nas grandes regiões e nos Estados para não perder a dimensão da conquista e da importância de se ter professores-educadores críticos, ousados, com autonomia, resistentes à imposição do capital (MEDEIROS, 2019).

\footnotetext{
${ }^{2}$ Promoção de Arquivamento no 351/2019 pelo Ministério Público Federal e Procuradoria da República no Distrito Federal, em 06 de junho de 2019, por Marcia Brandão Zollinger, Procuradora da República.
} 
Exemplos de Resistência na educação do campo são diversos. Destaco três como possibilidades de educação de resistência: 1) não permitir a adoção de materiais didáticos da Vale, da ABAG e de outras empresas que atuam em nome do agronegócio; 2) denunciar a realidade dos professores que hoje são criminalizados por defender a educação laica, pública e gratuita; 3) divulgar o que vem sendo feito nas escolas, como o direito de professores, estudantes e comunidades de terem autonomia.

Jornada da juventude - Em 2019, foi realizada a $10^{\mathrm{a}}$ Jornada da Juventude Sem Terra (MARINHO, 2019). Teve como lema: "Juventude em Luta: pela vida e por direitos!". Foi um profundo debate no Coletivo Nacional de Juventude sobre temas que afetam diretamente a juventude brasileira, por exemplo, a questão da violência do Estado, que tem afetado diretamente a juventude pobre, negra, do campo e da cidade, e a disposição de luta pela educação pública.

\section{Considerações finais}

Hoy quiero cantarte tierra mía
llenarte de elogios y de amor
con esta sencilla melodía
que al cantarla grita el corazón
Ay mi Ecuador, ay mi Ecuador,
donde quiera que vaya te llevó en mi corazón.

("De donde vengo", ALVEAR, 2015)

A defesa das políticas públicas, em especial da educação pública, gratuita, laica e de qualidade, em conformidade com o princípio de que "educação não é mercadoria", luta histórica da classe trabalhadora, é um lema que precisa estar ativo. Requer-se a organização da categoria dos trabalhadores da educação na perspectiva de uma práxis coletiva e de organização social para articulação e construção de outro projeto educacional.

A luta pela reforma agrária no Brasil, defendida pelo MST, tem uma relação histórica com as lutas do campo e da cidade. A luta pela realização da reforma agrária popular no Brasil deve ser pauta de toda a sociedade, considerando que modelos de agricultura de mercado, com concentração fundiária e de propriedade privada, são responsáveis pela pobreza, desigualdades, espoliação humana.

O contexto histórico e conjuntural é de luta, resistência, unidade e organização para a classe trabalhadora. A arte e a educação popular, no contexto atual, precisam ser consideradas instrumentos formadores e transformadores para o trabalho de base.

\section{Informações sobre a autora:}

Márcia Mara Ramos

(iD) https://orcid.org/0000-0001-6698-0169

(9) http://lattes.cnpq.br/3995871487712775

Doutoranda em Educação na Universidade do Estado do Rio de Janeiro - UERJ, pelo Programa de Pós-graduação (ProPEd-UERJ), com apoio da Fundação de Amparo à Pesquisa do Estado do Rio de Janeiro - FAPERJ e da Coordenação de Aperfeiçoamento de Pessoal de Nível Superior - CAPES. Mestre em Educação pelo Programa de Pesquisa em História, Sociedade e Educação no Brasil - Histedebr/UNICAMP. Especialista em Trabalho, Educação e Movimentos Sociais - EPSJV/FIOCRUZ. Licenciada em Educação do Campo, na área de Ciências Sociais e Humanidades - UFMG. Integra a área de estudos de pesquisa: Educação, Infância e Juventude. Linha de pesquisa: Infância e Saberes Docentes. Atualmente compõe o Coletivo Nacional de Educação do MST e atua como professora/educadora pesquisadora em Educação Educação do Campo e Infâncias do Campo nas áreas de assentamentos e acampamentos de reforma agrária.

\section{Como citar este artigo:}

\section{ABNT}

RAMOS, Márcia Mara. Educação popular: instrumento de formação, luta e resistência no projeto educativo do MST. Fractal: Revista de Psicologia, Niterói, v. 32, n. esp., p. 233-238, jun. 2020. https://doi.org/10.22409/1984-0292/v32_i-esp/40984

\section{APA}

Ramos, M. M. (2020, Junho). Educação popular: instrumento de formação, luta e resistência no projeto educativo do MST. Fractal: Revista de Psicologia, 32(esp.), 233-238. doi: https://doi. org/10.22409/1984-0292/v32_i-esp/40984

\section{Copyright:}

Copyright $(\subset 2020$ Ramos, M. M. Este é um artigo em acesso aberto distribuído nos termos da Licença Creative Commons Atribuição que permite o uso irrestrito, a distribuição e reprodução em qualquer meio desde que o artigo original seja devidamente citado.

Copyright (C) 2020 Ramos, M. M. This is an Open Access article distributed under the terms of the Creative Commons Attribution License, which permits unrestricted use, distribution, and reproduction in any medium, provided the original article is properly cited.

\section{Referências}

ALENTEJANO, Paulo; CORDEIRO, Tássia. 80 mil escolas no campo brasileiro foram fechadas em 21 anos. Brasil de fato, 29 nov. 2019. Disponível em: https://www.brasildefato.com. br/2019/11/29/artigo-or-80-mil-escolas-no-campo-brasileiroforam-fechadas-em-21-anos. Acesso em: 25 jan. 2020.

ALVES, Isabela. Agricultura familiar produz $70 \%$ dos alimentos consumidos por brasileiros. Observatório do Terceiro Setor, 30 abr. 2019. Disponível em: https://observatorio3setor. org.br/noticias/agricultura-familiar-produz-70-dos-alimentosconsumidos-por-brasileiros/. Acesso em: 18 fev. 2020.

ALVEAR, Alex. De donde vengo. Tv Cultura y Patrimônio Ecuador. Dirección: Christian Valencia. Producción: Lola Guevara, Dayana Mestanza y Christian Valencia. Youtube. 16 jun. 2015. 3min12s. Disponível em: https://www.youtube.com/ watch?v=vhipjc2sGP8. Acesso em: 14 out. 2019.

ASSOCIAÇÃO PARANAENSE DOS EXPOSTOS AO AMIANTO. Perigo: o Brasil é o maior consumidor de agrotóxicos do mundo. G1, 21 dez. 2017. Disponível em: https://g1.globo.com/pr/parana/especial-publicitario/apreaa/ noticia/perigo-o-brasil-e-o-maior-consumidor-de-agrotoxicosdo-mundo.ghtml. Acesso em: 13 nov. 2019. 
BARBOSA, Marcos. Educadores se posicionam contra despejo do Centro de Formação Paulo Freire. Movimento dos Trabalhadores Rurais sem Terra (MST), 19 set. 2019. Disponível em: https://mst.org.br/2019/09/19/educadores-seposicionam-contra-despejo-do-centro-de-formacao-paulofreire/. Acesso em: 22 dez. 2019.

DARDOT, Pierre; LAVAL, Christian. A nova razão do mundo: ensaio sobre a sociedade neoliberal. São Paulo: Boitempo, 2016.

DINIZ, Lília. O miolo de pote da cacimba de beber. Imperatriz, MA: Edição do autor, 2017.

HARVEY, David. O enigma do capital e as crises do capitalismo. São Paulo: Boitempo, 2012.

JIMÉNEZ, Carla. Extrema pobreza sobe e Brasil já soma 13,5 milhões de miseráveis. El país, 6 nov. 2019. Disponível em: https://brasil.elpais.com/brasil/2019/11/06/ politica/1573049315_913111.html. Acesso em: 17 jan. 2020.

MANCEBO, Deise. Contemporaneidade e efeitos de subjetivação. In: BOCK, Ana Mercês Bahia (Org.). Psicologia e compromisso social. São Paulo: Cortez, 2003. p. 75-92.

MARINHO, Gustavo. "Pela vida e por direitos": Jornada da Juventude defende a educação pública. Movimento dos Trabalhadores Rurais sem Terra (MST), 4 ago. 2019. Disponível em: https://mst.org.br/2019/08/04/pela-vida-e-pordireitos-jornada-da-juventude-defende-a-educacao-publica/. Acesso em: 20 nov. 2019.

MEDEIROS, Catiana de. Encontro discute a resistência ativa em escolas públicas do RS. Movimento dos Trabalhadores Rurais sem Terra (MST), 1 nov. 2019. Disponível em: https:// mst.org.br/2019/11/01/encontro-discute-a-resistencia-ativaem-escolas-publicas-do-rs/. Acesso em: 2 jan. 2020.

MST. Secretária Nacional do MST. Cartilha Programa Agrário do MST. VI São Paulo, 2014. Disponível em: https:// mstbrasilien.de/wp-content/uploads/2014/02/CartilhaPrograma-agr\%C3\%A1rio-do-MST-FINAL.pdf. Acesso em: 12 mar. 2020

PELO direito à literatura nas escolas do campo. Movimento dos Trabalhadores Rurais sem Terra (MST). Youtube. 17 sept. 2019. 6min56s. Disponível em: https://www.youtube.com/ watch? $v=$ gyxNzgBjX3Q. Acesso em: 21 jan. 2020.

ROSSLER, João Henrique. A educação como aliada da luta revolucionária pela superação da sociedade alienada. In: DUARTE, Newton. (Org.). Crítica ao fetichismo da individualidade. Campinas, SP: Autores Associados, 2004. p. 75-98.

TAIGUARA. Que as crianças cantem livres. Youtube, 7 abr. 2016. 3min5s. Disponível em: https://www.youtube.com/ watch? $\mathrm{v}=\mathrm{oEFPRTD} 6144$. Acesso em: 12 out. 2019.

TIERRA, Pedro. Fala da Terra. Dados e textos sobre a Luta pela Terra e a Reforma Agrária - Poesia. Modificado em: 29 abr. 2014. Disponível em: http://www.mstemdados.org/sites/ default/files/A\%20fala $\% 20$ da $\% 20$ terra $\% 20-\% 20$ Pedro $\% 20$ Tierra.pdf. Acesso em: 12 out. 2019. 